\title{
Examining Family Living Arrangements, Economic Development, Education Expenditure and Children's Weight from the Welfare Mix in China
}

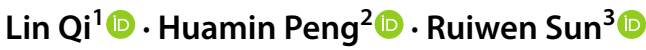

Accepted: 9 September 2021 /Published online: 14 October 2021

(c) The Author(s) 2021

\begin{abstract}
There is increased social concern regarding children's weight in China, but there is a relative lack of research concerning its social determinants. Based on 1,656 schoolage children's samples in mainland China from the Chinese Nutrition and Health Database (CHNS 2011), we analyzed the impact of multiple factors on children's weight using a welfare mix framework that integrated factors including family living arrangements, economic development, and educational spending. School-age children's weight was measured using body mass index (BMI). The independent variables were factors developed based on the social determinants of health perspective in conjunction with a welfare mix framework. These variables included family living arrangements to reflect the family welfare factor, average government educational expenditure per student to reflect the state welfare factor, and GDP per capita to reflect the market welfare factor. Multiple regression models were used to analyze the influences of each factor on children's weight. The results showed that the factors were significant, with different directions of influence on weight. The results also showed that the factors considered in the welfare mix framework sometimes serve as risk factors rather than solely protective factors within the Chinese context. According to this study, a reasonable geographical distribution of health service resources and child-oriented health policies are needed to promote children's well-being.
\end{abstract}

Keywords Health and weight $\cdot$ Welfare mix $\cdot$ Family living $\cdot$ Economic development $\cdot$ Education expenditure $\cdot$ Chinese children

Huamin Peng

penghm@nju.edu.cn

1 Crawford School of Public Policy, Australian National University, Canberra, Australia

2 Department of Social Work and Social Policy, Nanjing University, Nanjing, China

3 Institute of Social Development, Nanjing University, Nanjing, China 


\section{Introduction}

Overweight and obesity in school-age children have become significant public health challenges in China (Chen et al., 2017; China Obesity Task Force, 2004). According to health trend data collected among Chinese children aged 7 to 17 , between 1982 and 2002, the share of overweight children was $1.2 \%$ in 1982 and $4.4 \%$ in 2002 (Song et al., 2017). A recent study among Chinese school-age children has demonstrated a dramatic increase in the obesity rate from 1985 to 2010 , which raised from $0.10 \%$ to $4.3 \%$ under the World Health Organization (WHO)'s definition of obesity and from $0.03 \%$ to $2.2 \%$ under the definition of obesity proposed by the International Obesity Task Force (IOTF) (Song et al., 2017). To address this increasing trend of overweight and obesity among Chinese schoolage children, the Chinese government established the Working Group on Obesity in China (WGOC) in 2002. In 2018, WGOC published guidelines on overweight and obesity screening among children and adolescents in primary and middle schools (National Health \& Family Planning Commission of the People's Republic of China, 2018). It is clear from the efforts of the Chinese government along with the health trend data that physical wellness, particularly concerning weight, among Chinese school-age children has gradually become a social issue in need of further exploration.

Several studies have shown the impact of social and economic factors on children's weight health. Cobham et al. (2012) revealed the influence of economic development and social inequality on children's weight. In China, children encounter the challenges of economic and social inequality throughout their development (Gong \& Li, 2013). Chinese children witnessed the economic transformation from a planned economy institution to a market economy institution with potentially increased socioeconomic inequality during their childhoods. They also experienced the transformation of the Chinese social welfare system (Mok et al., 2017). In addition to institutional transitions, school-age children witnessed a series of social changes, for instance, in parental social status as a result of social mobility (Bian, 2002; Hu et al., 2010; Zhou et al., 1998) and changes in family arrangements (Thornton \& Fricke, 1987; Whyte, 1992). Thus, in consideration of the potential social and economic impact, it is essential to examine children's weight within the socioeconomic context.

Multiple countries and world organizations have emphasized the importance of physical wellness and have devoted efforts to collecting data on the weight of school-age children via large-scale surveys. These data have facilitated research regarding the impact of socioeconomic change on health and its policy implications to improve child well-being. WHO developed health surveys across several countries (Liu et al., 2010). The United States designed the National Health and Nutrition Examination Survey (NHANES) in the 1960s to evaluate the health and nutritional status of adults and children in the U.S., and the survey later became a long-lasting program concerning various health and nutrition measurements after 1999 (Borrud et al., 2014; Center for Disease Control to Evaluate Trends in Obesity, 2010). Japan started its National Nutrition Survey in the 1940s to monitor the 
nutrition and health status of the Japanese population, and the survey was later renamed the National Health and Nutrition Survey (Sasaki, 2011; Yoshiike et al., 1996). Australia initiated the National Children's Nutrition and Physical Activity Survey in 2005 to capture information regarding diet, nutrition, physical activity, and children's weight (Commonwealth Scientific Industrial Research Organization, 2008; Wang et al., 2019). China launched the China Health and Nutrition Survey (CHNS) in 1989 to collect information on its population's nutritional and health status-including children-and examine possible mezzo and macro impact factors of health and nutritional status (CHNS, 2020). Each of these studies, and the datasets they produce, help to facilitate a global effort in researching children's weight and its predictors to improve overall child well-being.

\section{Literature Review, Research Questions and Hypotheses}

\section{Children's Physical Health in Regards to Weight}

There are international surveys and indexes currently used to measure children's weight (Cole et al., 2000). BMI is one such index and is as an essential worldwide criterion to measure an individual's health with regard to weight. BMI, constructed by relatively objective weight and height indicators, can also be applied to measure children's weight. The index is also used to differentiate between overweight and obesity through a variety of calculation methods and criteria. Based on BMI, WHO has further computed BMI-for-age Z-score and BMI-for-age percentile for children aged 5-19 (WHO, 2007). Similarly, based on BMI, IOTF has performed studies on overweight and obesity and generated related standards. WGOC has also conducted related studies (Song et al., 2017).

In 2001, WHO published the International Classification of Functioning, Disability and Health (ICF) and enacted a children and youth version (ICF-CY) to reflect children's unique traits (Qiu et al., 2014; WHO, 2001). Based on large datasets, the study utilized the age-specific sex BMI recommended by IOTF to define overweight and obesity in children ( $\mathrm{Li}$ et al., 2008). Gonzalez-Casanova et al. (2013) found that IOTF, the United States Centers for Disease Control and Prevention (CDC), and WHO developed three different BMI classification systems to measure overweight and obesity. After comparing variations of the BMI criteria established by WGOC, WHO, IOTF, and CDC, Zhang et al. (2009) further claimed that WHO measures were more applicable for overweight and obesity screening in Chinese school-age children with higher sensitivity, specificity, and agreement rate.

The BMI-for-age percentile index is more applicable than BMI in evaluating children's weight because the BMI-for-age percentile controls for age difference. To establish national BMI criteria for screening and examining overweight and obesity rates among Chinese children based on the BMI-for-age percentile, China Obesity Task Force (2004) used the 2000 Chinese National Survey on Students Constitution and Health as its reference population, with a sample of more than 244,200 primary and middle school-age students. By comparing the BMI distribution of various Chinese children and adolescent groups with the international norm developed by 
the U.S. NCHS, the research found that the prevalence of overweight and obesity was subject to gender and regional differences (China Obesity Task Force, 2004). In addition, in terms of BMI by age and sex as recommended by the IOTF, research has found that overweight and obesity rates have been rapidly increasing since 1992 ( $\mathrm{Li}$ et al., 2008; Song et al., 2017). Data analysis results based on CHNS and the China Nutrition Transition Cohort Study demonstrated that childhood overweight in China was not severe in comparison with that in developed countries. However, comprehensive policies and preventive interventions with the goal of reducing overweight and obesity rates, ultimately promoting healthy weight among children in China, are still needed.

\section{Family and Children's Physical Health in Regards to Weight}

Studies on the correlation between children's health and family socioeconomic status (SES) have found that the significant increase in the prevalence of childhood obesity in recent decades is associated with socioeconomic factors. Using data from NHANES from 1999 to 2006, Murasko (2009) analyzed the role of family SES in America in childhood obesity. He found that childhood obesity was inversely related to family SES; thus, children in low-income families with low SES were more likely to suffer from obesity. This effect of family SES was most pronounced in white male and Hispanic female children. From 1991 to 2009, the rates of under- and overweight in Chinese children respectively increased by 1.22 times and 0.39 times (Tang et al., 2014). During this period, considering children's weight issues, family income shifted from being a protective factor to a potential risk factor, and parental education became increasingly prominent (Tang et al., 2014). Another study integrated the principles of health economics, social epidemiology, and health behaviors by analyzing the impact of Chinese family socioeconomic factors on childhood overweight in China (Zhang et al., 2018). In this study, it was found that children with higher family SES demonstrated increased rates of overweight and obesity between 1991 and 2006 (Zhang et al., 2018).

Changes in socioeconomic factors such as China's rapid economic growth, increasing population mobility, and severe income inequality have made the factors affecting physical health much more complicated. Research results on the impact of individual traits, regional socioeconomic factors, and income inequality on overweight and obesity have shown that at the individual level, income and wealth were positively correlated with obesity, while higher education level and physical labor were both protective factors (Zhang, 2012). At the regional level, lower levels of poverty within one's community can reduce obesity risk, while higher levels of urbanization elevated the risk of obesity (Zhang, 2012). Another study found that migrant parents leaving home had an impact on children's health services, education, mental health and physical health (Lee, 2011). The study found that parental mobility negatively affected children's access to health services and overall health condition, further finding that parental absence due to mobility had a more significant influence on children's mental health than their physical health (Lee, 2011). 
These findings aid in understanding the impact of socioeconomic factors on health, especially in developing countries.

\section{Social Determinants of Health and Welfare Mix}

WHO established the Commission on Social Determinants of Health (CSDH) in 2005 and identified in its "Social Determinants of Health Report" submitted in 2008 that social determinants of health for members in society include but are not limited to social status, education, occupation, income, social protection, socioeconomic policy, and social cohesion and that taking action can protect health while eliminating health inequality (WHO, 2011; WHO CSDH, 2008). Other social determinants of health framework stated that factors such as education, community and social spheres, economic stability, health care, and neighborhood and environment have the ability to impact and improve the health of members of society (Doyle et al., 2018). Solar and Irwin (2010) claimed that social determinants of health consist of socioeconomic factors, circumstances (living and working conditions, food availability), and policy along with social norms, social cohesion and social capital. By using economic development, social inequality, child health, and other specific measures, a 2012 study using the Child Development Index validated the impact of socioeconomic factors on children's health (Cobham et al., 2012).

The welfare mix perspective is a theoretical framework for analyzing social determinants that emphasizes the participation of the state, market, family, community, and the third sector in providing welfare. According to Evers, the state, family, and market constitute the welfare triangle, and welfare obtained by individuals is the sum of state-social welfare, family welfare, and market-economic welfare (Evers, 1990). Evers (1995) later incorporated the third sector into the welfare mix and defined the third sector as an intermediate area. Shared welfare responsibilities among the state, family, market, and third sector were emphasized (Evers, 1995; Evers \& Laville, 2004). Multiple sources of welfare guarantee improved human well-being. However, market, family, community and third sector welfare were not substitutes for state welfare (Beresford \& Croft, 1983; Johnson, 1987). Longo et al. (2015) found that in Italy, public institutions, private providers, and families make up the healthcare and service delivery system, providing a model welfare resource mix. Germany combines formal institutionalized care and informal family care services in its longterm care insurance network, with family members identified as vital care providers (Theobald, 2012). A comparative welfare provision study between the Netherlands and China argued for the merits of a multilevel public-private sector mix in welfare provision, with a focus on healthcare services, social housing, and pension provision/elderly care services (van Montfort et al., 2018).

Children are important welfare recipients. The United Nations Children's Fund (United Nations, 1959, 1989) has clearly stated in its Declaration on the Rights of the Child and the subsequent Convention on the Rights of the Child that children need special protection as the most vulnerable group. The United Nations (1989) defined the age range of children as 0 to 18 years old. On the other hand, Chinese policy has defined children as those falling within the range of 0 to 14 years old. 
The Chinese government has established policies on child rearing for children living in under adverse environmental, living security, education, and medical care conditions (Ministry of Civil Affairs of the People's Republic of China, 2013), forming a narrowly defined social welfare system for children. As children do not have sufficient capacity to obtain benefits from a competitive market, family and social welfare provision are the guarantees of their health and growth (United Nations, 1959, 1989). From a social development perspective, Peng (2011) and Shang (2010) identified that Chinese social welfare policy and the defined age range were not in line with international standards and that children's education, medical insurance and services should be integrated into the social welfare system to ensure delivery of child welfare, thereby protecting children's health. International research on Chinese social welfare has mostly used the concept of general social welfare. For example, Mok et al. (2017) held that the Chinese government focused on productive social welfare in education and medical care, leading to a selective welfare system.

\section{Research Questions}

Through this literature review, we find that research on Chinese school-age children's physical health with regard to weight fails to provide insight into the mutual interactions of multiple factors at both the micro and macro levels-such as family factors, market factors, and state factors-in analyzing children's weight. Based on the contributions and limitations of previous research, this study builds upon the welfare mix framework proposed by Evers $(1990,1995)$, in conjunction with the conceptual framework of social determinants of health (Solar \& Irwin, 2010; WHO CSDH, 2008), by pairing the aforementioned social determinants of health with various sources of welfare-social capital (family welfare) provided by the family, education (social welfare) provided by the state, and economic (market) welfare provided by market. Thus, this article analyzes social determinants of health from the welfare mix perspective, focusing on three types of welfare factors and their corresponding providers. This study adopts the United Nations definition of children (0 to 18 years old) and mainly focuses on school-age children, which includes primary school children aged 6-12 and junior and senior high school children aged 13-18. Four research questions are raised as follows:

(1) How do family living arrangements (our indicator of family welfare) affect Chinese school-age children's weight?

(2) How does the regional economic development level (our indicator of market welfare) influence Chinese school-age children's weight?

(3) What impact does the regional education welfare level (our indicator of state welfare) have on Chinese school-age children's weight?

(4) Are the family welfare, market welfare, and state welfare components of the welfare mix model all protective factors in regards to Chinese school-age children's weight? 


\section{Research Hypotheses}

The welfare mix theory proposed by Evers $(1990,1995)$ integrates macro-level variables such as state welfare and market welfare and different micro-level welfare variables into the same research framework for analysis, which aims to show that the total welfare received by individuals comes from providers at different levels. Studies on public attitudes in Germany and the United Kingdom suggested that the state, market, and families should share welfare responsibilities (Heuer et al., 2016). According to the welfare mix theory, we designed the macro variables-including state welfare and market welfare-and the micro variable family welfare.

Among studies on the welfare mix, market welfare as measured by data on GDP or GDP per capita and state welfare - that includes education spending, pension, medical insurance, social assistance, etc. - were used to analyze the relationship between economic development and social welfare in a country or region (Edmiston, 2011; Maruo, 2006; Powell \& Barrientos, 2010). Based on previous studies and in consideration of geographic differences among school-aged children, we selected GDP per capita that revealed different levels of regional development as the market welfare variable. Further, we adopted government education expenditure on students that reflected welfare delivery levels by different regional governments as the state welfare variable.

As a contribution, the welfare mix theory incorporated family welfare into the total welfare received by individuals. Family welfare has played a critical role in children. An (2013) indicated that family has been the main sector for childcare despite increased time in childcare being provided by the market welfare sector and the state welfare sector in Japan and Korea. Studies on the effect of the family environment on childhood obesity have focused on parental weight status (Hendrie et al., 2012; Jiang et al., 2013), parental physical activity (Hendrie et al., 2012), and parental socioeconomic status (Huang et al., 2017), with rare emphasis on family living arrangements. Thus, guided by welfare mix theory, this study adopts family living arrangements as the family welfare variable to reflect family structure and parental involvement.

Based on welfare mix theory and relevant studies, this research focuses on the dynamics between macro- and micro-factors, which lead to the following hypotheses:

Hypothesis 1: Chinese school-age children's weight is associated with family living arrangements (our indicator of family welfare).

Hypothesis 2: Chinese school-age children's weight is associated with GDP per capita (our indicator of market welfare).

Hypothesis 3: Chinese school-age children's weight is associated with governmental education expenditure per student (our indicator of state welfare).

\section{Methodology}

\section{Data}

This article uses data from CHNS, which was jointly designed by the Chinese Academy of Preventive Sciences and the University of North Carolina, aimed at 
investigating how social and economic reforms in China are affecting the health and nutritional status of the population (CHNS, 2020). CHNS is a longitudinal study with ten completed surveys (from 1989, 1991, 1993, 1997, 2000, 2004, 2006, 2009, 2011, and 2015). In 2011, CHNS survey used a multistage, random cluster process to draw a sample of households with individuals in 12 provinces and municipal cities in mainland China, including Beijing, Chongqing, Guangxi, Guizhou, Heilongjiang, Henan, Hubei, Hunan, Jiangsu, Liaoning, Shandong, and Shanghai; thus, its sample shows relatively appropriate national representativeness. Since data for BMI calculation are not publicly available in the 2015 dataset, this study utilizes the data collected in 2011 to examine the BMI of Chinese school-age children and its socioeconomic determinants. Considering that state welfare can be reflected through the government's financial investment in education, this study selects only children who were receiving education, leading to a sample size of 1,656 children aged 6 to 18 . This study is based on a secondary analysis of published official data-GDP per capita of provinces and average government spending on education-from the China Statistical Yearbook 2012 (National Bureau of Statistics of the People's Republic of China, 2012) and the China Education Statistical Report 2011 (Ministry of Education of the People's Republic of China, 2012).

\section{Method}

\section{Dependent Variable}

In this study, BMI-for-age percentile is used as the dependent variable. This study generates BMI values using the BMI calculation formula (see below) along with the height and weight data collected in CHNS 2011. To minimize the impact of age and gender in interpreting BMI readings, this study adopts the scale and calculating tools provided by the WHO growth reference data for children 5-19 years old (WHO, 2007) and further synthesizes BMI-for-age percentile with CHNS 2011 data based on school-age children's age, gender, weight, and height. The CHNS 2011 data were collected via a questionnaire survey conducted by professional researchers using stratified random sampling. In line with a study conducted by China Obesity Task Force (2004), weight was further categorized-based on school-age children's age, sex, weight, and height-into two groups: one subgroup consisted of normal- and low-weight children, while the other group included overweight and obese children.

$$
B M I=\text { Weight }(\mathrm{kg}) / \text { HeightSquared }(\text { sqm })
$$

\section{Independent Variables}

Based on WHO's proposed framework of the social determinants of health (WHO CSDH, 2008), in conjunction with a welfare mix perspective (Evers, 1990, 1995), this study establishes three types of independent variables: family welfare, state welfare, and market welfare factors. (1) The family welfare factor is measured by four types of family living arrangements that provide family care benefits to 
school-age children: living with father and mother, living with father only, living with mother only, and living without father or mother. (2) The state welfare factor is measured by the governmental education expenditure per student of the 12 provinces and municipal cities where respondents were located. This study further specifies the governmental education expenditure per student by different levels of education, focusing on primary school students, junior high school students, and senior high school students. (3) To measure the market welfare factor, we utilize the GDP per capita of the 12 provinces and municipal cities in which the respondents were located. The family living arrangement variables are computed via data from CHNS 2011, while governmental education expenditure per student and GDP per capita are gathered from government statistics (Table 1).

Table 1 Description of variables

\begin{tabular}{lc}
\hline Variables & Description \\
\hline $\begin{array}{l}\text { Dependent variable } \\
\text { School-age children's weight } \\
\text { BMI-for-age percentile }\end{array}$ & \\
& $\begin{array}{l}\text { School-age children's BMI-for-age percentile } \\
\text { (WHO, 2007) } \\
\text { School-age children's normal + low weight, } \\
\text { overweight + obesity (China Obesity Task Force, } \\
\text { 2004) }\end{array}$
\end{tabular}

Independent variables

Family welfare factors

Live with parents

School-age children living with father $\&$ mother

Live with Father Only

Live with Mother Only

Live without parents

School-age children living with father only

School-age children living with mother only

State welfare factor

Governmental education expenditure per student of provinces (including autonomous regions and municipalities)

School-age children living without father or mother

Market welfare factor

GDP per capita of provinces (including autonomous regions and municipalities)

CHNS 2011 was conducted in the 12 provinces and municipal cities, including Beijing, Chongqing, Guangxi, Guizhou, Heilongjiang, Henan, Hubei, Hunan, Jiangsu, Liaoning, Shandong, and Shanghai

Governmental education expenditure per student is measured by different levels of education-primary school, junior high school, and senior high school-based on government statistics

CHNS 2011 was conducted in the 12 provinces and municipal cities, including Beijing, Chongqing, Guangxi, Guizhou, Heilongjiang, Henan, Hubei, Hunan, Jiangsu, Liaoning, Shandong, and Shanghai

GDP per capita of provinces (including autonomous regions and municipalities) are gathered from government statistics 


\section{Data Analysis Strategy}

First, the BMI-for-age percentile data of 1,656 samples are calculated with the WHO tool (WHO, 2007). Second, we analyze descriptive statistics on the schoolage children's sex, age, and weight by living family structure based on the CHNS 2011 dataset. Third, we conduct descriptive analyses of GDP per capita and governmental education expenditure per student across the 12 provinces and municipal cities where the respondents were located. Finally, we examine the effects of the four family living arrangements, GDP per capita and education spending per student on the BMI-for-age percentile of the 1,656 students by regression analysis. OLS analysis is conducted using a regression model in Stata 14.

\section{Results}

\section{Basic Descriptive Statistics}

Based on the CHNS 2011 database, the study sample consists of 1,656 participants aged 6 to 18 . There are 847 boys $(51.1 \%)$ and 809 girls (48.9\%). There are 1,059 primary school children $(63.9 \%)$ and 597 junior and senior high school children (36.1\%). There are 708 school-age children living in cities (42.8\%) and 908 schoolage children living in rural areas $(57.2 \%)$, demonstrating a reasonable sample distribution. Based on the BMI reference norm for screening overweight and obesity in Chinese children (China Obesity Task Force, 2004), this study calculates that 278 school-age children were overweight and obese (16.8\%) and 1378 were of normal or low weight (83.2\%) (Table 2).

Table 2 Descriptive statistics of school-age children's sex, age, weight by family living arrangements

\begin{tabular}{|c|c|c|c|c|c|c|c|c|c|c|}
\hline \multirow[t]{2}{*}{ Variables } & \multicolumn{2}{|c|}{$\begin{array}{l}\text { Living with } \\
\text { father \& mother }\end{array}$} & \multicolumn{2}{|c|}{$\begin{array}{l}\text { Living with } \\
\text { father only }\end{array}$} & \multicolumn{2}{|c|}{$\begin{array}{l}\text { Living with } \\
\text { mother only }\end{array}$} & \multicolumn{2}{|c|}{$\begin{array}{l}\text { Living with- } \\
\text { out parents }\end{array}$} & \multicolumn{2}{|l|}{ Total } \\
\hline & $n$ & $\%$ & $n$ & $\%$ & $n$ & $\%$ & $n$ & $\%$ & $n$ & $\%$ \\
\hline $\begin{array}{l}\text { Living Arrangement } \\
\text { Sex }\end{array}$ & 1160 & 70.05 & 77 & 4.65 & 184 & 11.11 & 235 & 14.19 & 1656 & 100 \\
\hline Boy & 599 & 70.72 & 37 & 4.37 & 96 & 11.33 & 115 & 13.58 & 847 & 100 \\
\hline Girl & 561 & 69.34 & 40 & 4.94 & 88 & 10.88 & 120 & 14.83 & 809 & 100 \\
\hline Age & & & & & & & & & & \\
\hline Age 6-12 & 698 & 65.91 & 46 & 4.34 & 130 & 12.28 & 185 & 17.50 & 1059 & 100 \\
\hline Age13-15 & 274 & 74.25 & 20 & 5.42 & 36 & 9.76 & 39 & 10.60 & 369 & 100 \\
\hline Age16-18 & 188 & 82.46 & 11 & 4.83 & 18 & 7.90 & 11 & 4.83 & 228 & 100 \\
\hline Weight & & & & & & & & & & \\
\hline Overweight \& Obese & 208 & 74.82 & 4 & 1.44 & 29 & 10.43 & 37 & 13.31 & 278 & 100 \\
\hline Normal \& Low weight & 952 & 69.09 & 73 & 5.30 & 155 & 11.25 & 198 & 14.37 & 1378 & 100 \\
\hline
\end{tabular}

$N=1656$. Data based on CHNS 2011 dataset 


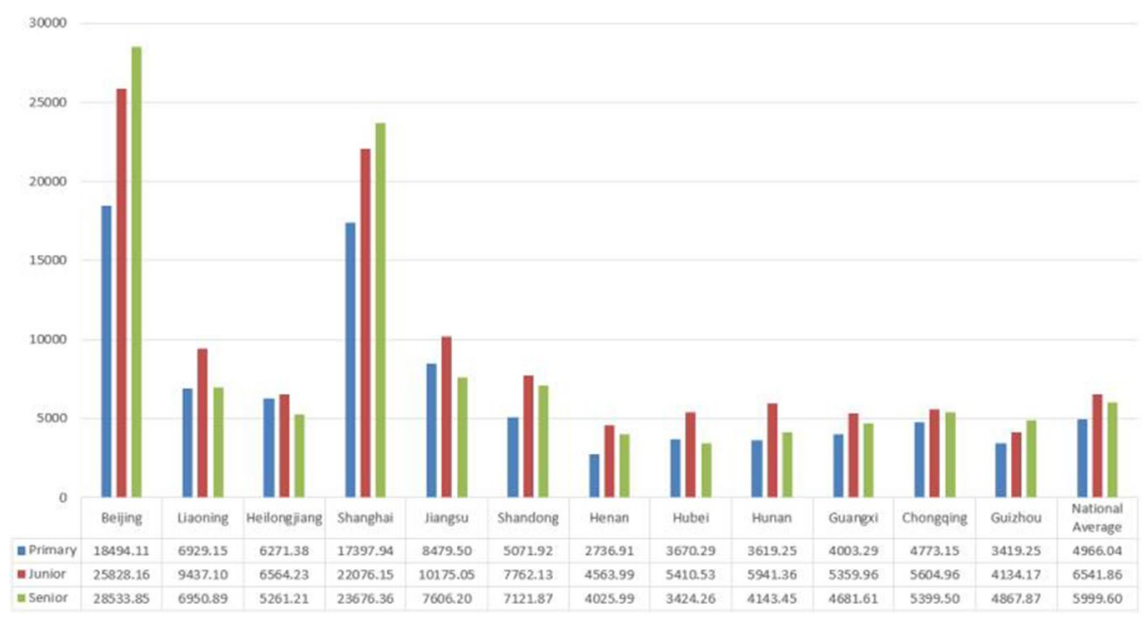

Note. We calculated governmental education expenditure per student of the 12 provinces and municipal cities where CHNS 2011 respondents were located, according to government statistics (Ministry of Education of the People's Republic of China, 2012)

Fig. 1 Governmental education expenditure per student of the 12 provinces and municipal cities where the samples were located

In this study, we use governmental education expenditure per student and GDP per capita in 2011 as independent variables to study their influence on school-age children's weight. In 2011, the governmental education expenditure per student nationwide was 4,964.04 yuan for primary schools, 6,541.86 yuan for junior high schools, and 5,999.60 yuan for senior high schools. Among the 12 provinces and municipal cities where the 1,656 students were located, Beijing, Shanghai, Jiangsu, Liaoning, and Shandong had higher governmental education expenditures per student for all three levels of education than the national average in the sample period. The averages per student for both primary and junior high school in Heilongjiang Province were slightly higher than the national average, while those for senior high school fell below the national average. Meanwhile, Hainan, Hunan, Hubei, Guangxi, Chongqing, and Guizhou had lower governmental education expenditures per student for all three levels of education than the national expenditure level (Fig. 1). The average per primary school student in Beijing was the highest among all 12 areas and 6.76 times higher than that in Henan Province, which had the lowest average per primary school student. The governmental education expenditure per junior high school student in Beijing was the highest among all 12 areas and was approximately 4.84 times higher than that in Guizhou Province, which had the lowest average per junior high school student. The governmental education expenditure per senior high school student in Beijing was the highest among all 12 areas and was 8.33 times higher than that of Hubei Province, which had the lowest average per senior high student.

GDP per capita in 2011 followed a similar geographic pattern to that of the governmental education expenditure per student. The GDP per capita of Beijing, 


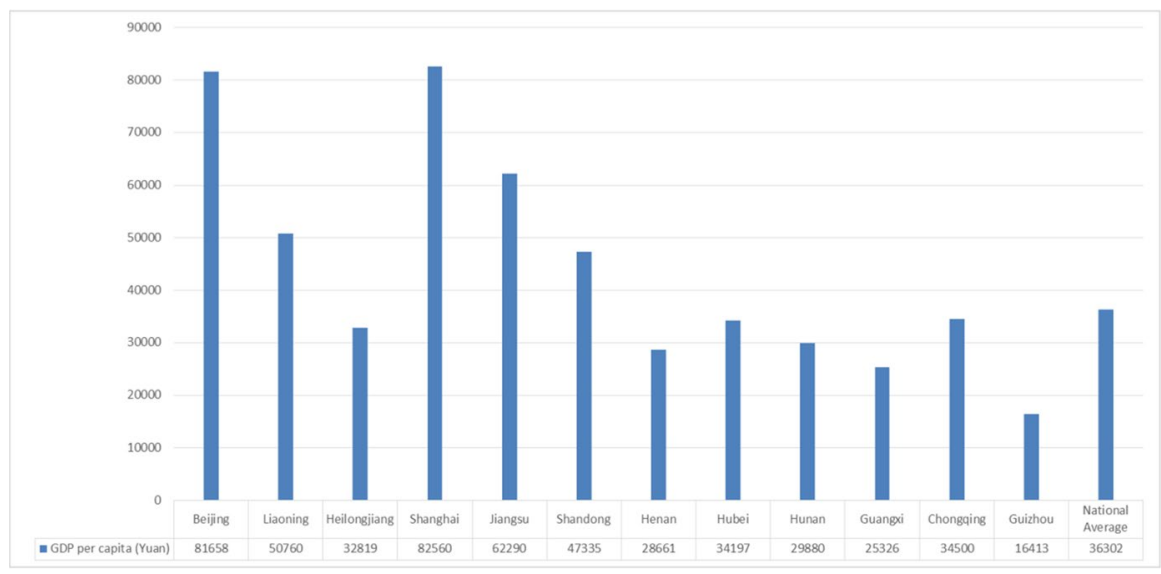

Note. We calculated GDP per capita of the 12 provinces and municipal cities in which the CHNS 2011 respondents were located, according to government statistics (National Bureau of Statistics of the People's Republic of China, 2012)

Fig. 2 GDP per capita (yuan) in the 12 provinces and municipal cities where the samples were located

Shanghai, Jiangsu, Liaoning and Shandong was higher than the national average; the indicators for other provinces and municipalities, such as Heilongjiang, Hainan, Hunan, Hubei, Guangxi, Chongqing, and Guizhou, were below the national average (Fig. 2). Shanghai had the highest GDP per capita, which was 5.03 times as high as that of Guizhou Province, which had the lowest GDP per capita in 2011 (Fig. 3). The comparative data on the governmental education expenditure per student and GDP per capita in 2011 demonstrate a geographically unequal distribution of socioeconomic resources. The provinces, municipalities and autonomous regions with high GDP per capita were also those with high governmental education expenditure per student. Therefore, when GDP per capita and governmental education expenditure per student is put into the same regression analysis model, the endogeneity of these two variables may affect their explanatory power.

Among the 12 areas where the 1,656 students were located, the analysis of Figs. 1 and 2 reveals that GDP per capita was associated with governmental education expenditure per student, with areas with higher GDP per capita reporting more governmental education expenditure per student (Fig. 3). Further analysis reveals that areas with high GDP per capita and governmental education expenditure per student display a relatively high proportion of overweight and obese students (Fig. 4). Beijing and Shanghai, the two cities ranked first and second in GDP per capita, also ranked first and second in governmental education expenditure per student in primary, junior and high school education. The proportions of overweight and obese children in these two cities ranked second and third, respectively.

GDP per capita was below the national average in Guizhou, Chongqing, Hunan, Guangxi, Hubei, and Henan, where governmental expenditure per student in primary, junior and high school education was also below the national average in 2011. In these six areas, the proportions of overweight and obese children rank twelfth, 


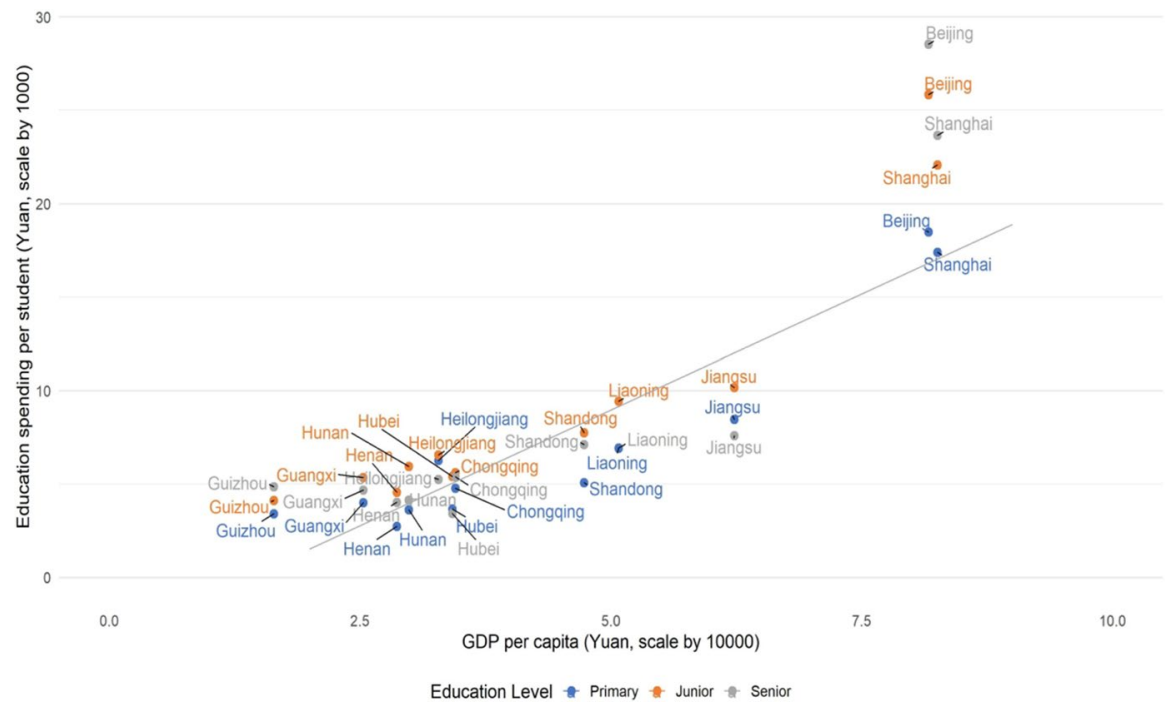

Note. We calculated data based on government statistics (Ministry of Education of the People's Republic of China, 2012; National Bureau of Statistics of the People's Republic of China, 2012)

Fig. 3 Relation between governmental education expenditure per student and GDP per capita

sixth, ninth, eleventh, seventh, and tenth, respectively. In Liaoning, Jiangsu, and Shandong, GDP per capita and governmental education expenditure per student at all three educational levels-primary, junior, and high school education-were all lower than those in Beijing and Shanghai but higher than the national average.

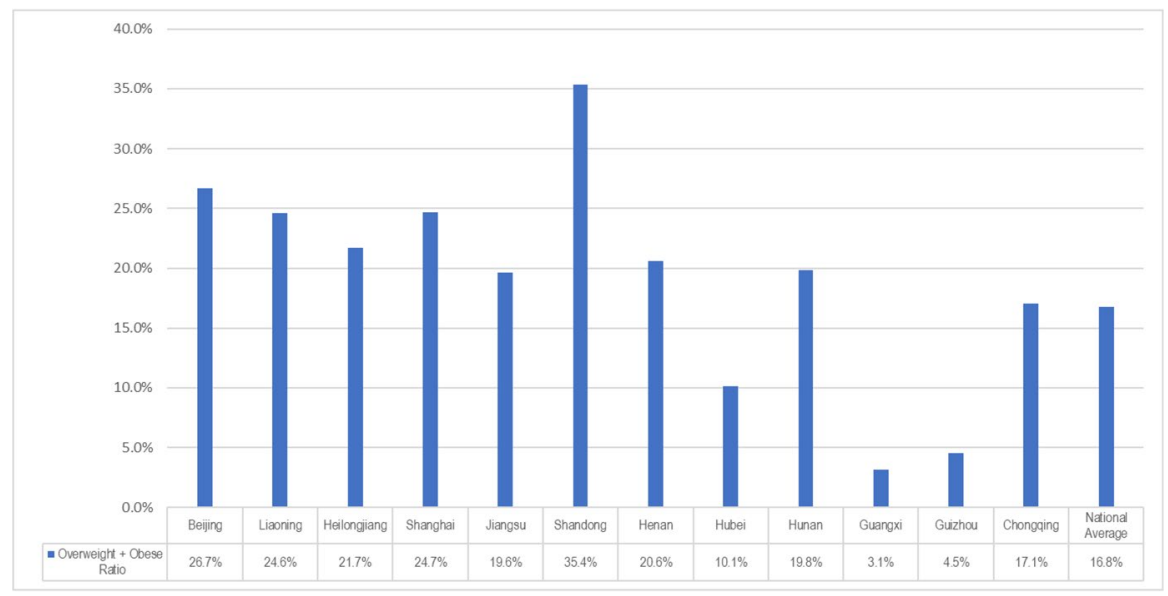

Note. Data based on CHNS 2011 dataset

Fig. 4 Proportion of obese and overweight children among the 12 provinces and municipal cities where the samples were located 
Table 3 Regression analysis of school-age children's weight on family living arrangements, GDP per capita and governmental education expenditure per student

\begin{tabular}{|c|c|c|c|c|}
\hline \multirow[b]{3}{*}{ Independent Variables } & \multicolumn{4}{|c|}{ BMI-for-age percentile } \\
\hline & \multicolumn{2}{|l|}{ Model 1} & \multicolumn{2}{|l|}{ Model 2} \\
\hline & $\bar{\beta}$ & $\overline{\text { Robust SE }}{ }^{\mathrm{d}}$ & $\bar{\beta}$ & Robust SE $^{\mathrm{d}}$ \\
\hline \multicolumn{5}{|l|}{ Family living arrangements ${ }^{a}$} \\
\hline Living with father only & $-10.90 * * *$ & 3.41 & $-13.25 * * *$ & 3.45 \\
\hline Living with mother only & -1.56 & 2.54 & -1.78 & 2.58 \\
\hline Living without parents & $5.17 * *$ & 2.38 & $4.54 *$ & 2.40 \\
\hline GDP per capita, scale by $10,000^{\mathrm{b}}$ & $3.66 * * *$ & 0.35 & & \\
\hline $\begin{array}{l}\text { Governmental education expenditure } \\
\text { per student, scale by } 1000^{c}\end{array}$ & & & $0.84 * * *$ & 0.12 \\
\hline $\mathrm{N}$ & 1656 & & 1656 & \\
\hline $\mathrm{F}$ & $34.46 * * *$ & & $18.81 * * *$ & \\
\hline
\end{tabular}

a $0=$ living with both father and mother. Data based on CHNS 2011 dataset. ${ }^{\mathrm{b}}$ We calculated GDP per capita of the 12 provinces and municipal cities in which the CHNS 2011 respondents were located, according to government statistics (National Bureau of Statistics of the People's Republic of China, 2012). ${ }^{\mathrm{c}}$ We calculated governmental education expenditure per student of the 12 provinces and municipal cities where CHNS 2011 respondents were located, according to government statistics (Ministry of Education of the People's Republic of China, 2012). ${ }^{\mathrm{d}}$ Robust SE is calculated from White estimator ${ }^{*} p<.1 .{ }^{* *} p<.05 .{ }^{* * *} p<.01$

The rankings of the proportions of children experiencing overweight and obesity in Liaoning, Jiangsu, and Shandong are fourth, third, and fifth, respectively. Uniquely, Heilongjiang, ranking eighth in the proportions of overweight and obese children among all areas where the students were located, had a lower than national average GDP per capita, a higher than national governmental education expenditure per student in primary education, and a lower than national governmental education expenditure per student in junior and high school education.

By analyzing GDP per capita, governmental education expenditure per student, and the ranking of the proportions of overweight and obese children in the areas investigated, this study identifies the geographical distribution of overweight and obese school-age children. In areas with a developed economy and high education expenditures, the proportions of overweight and obese children are also high. This finding further supports the findings of Table 3 that school-age children's weight is related to GDP per capita and education expenditure per student.

\section{OLS Regression: Family Living Arrangements, GDP per Capita, Governmental Education Expenditure per Student and School-Age Children's Weight}

In Model 1, there is a significant negative relationship between school-age children's weight and living with the father only $\left(\beta=-10.90^{* * *}\right)$, indicating that school-age children who live alone with their fathers are more likely to experience normal or lower weight than school-age children who live with both parents. No significant 
relationship is detected between school-age children's weight and living with the mother only in comparison with living with both parents $(\beta=-1.56)$, while schoolage children living with neither parent are more likely to experience overweight and obesity $\left(\beta=5.17^{* *}\right)$. Thus, the statistical results of Model 1 show that school-age children's weight is related to family living arrangements and substantiate Hypothesis 1 .

In Model 2, this study finds a significant negative relationship between schoolage children's weight and living with the father only $(\beta=-13.25 * * *)$, no significant relationship between school-age children's weight and living with the mother only $(\beta=-1.78)$, and a significant positive relationship between school-age children's weight and living with neither parent $(\beta=4.54 *)$. Model 1 and Model 2 are consistent in their findings. In comparison with school-age children living with both parents, school-age children living with the father only are more likely to have normal or lower weight; school-age children living with neither parent are more susceptible to overweight and obesity, and children living with only the mother show no statistically significant difference with regard to weight. Thus, Model 2 also substantiates Hypothesis 1.

Economic development and social welfare factors clearly affect Chinese schoolage children's weight. Based on Model 1, the regression analysis results demonstrate a positive relationship between school-age children's weight and GDP per capita $(\beta=3.66 * * *)$, indicating that school-age children from areas with higher GDP per capita are more likely to experience overweight and obesity. Based on Model 2 , school-age children's weight has a significant positive relationship with the governmental education expenditure per student $(\beta=0.84 * * *)$, which indicates that school-age children from areas with higher governmental education expenditure per student are more susceptible to the challenges of overweight and obesity. Models 1 and 2 show that the state welfare factor (GDP per capita) and the social welfare factor (governmental education expenditure per student) affect school-age children's weight in the same direction, further indicating that these factors may serve as risk factors rather than protective factors for childhood overweight. Thus, Model 1 substantiates Hypothesis 2, and Model 2 substantiates Hypothesis 3.

\section{Discussion}

Compared with previous studies, this study introduces social context based on the welfare mix perspective to analyze health-related data under WHO guidelines and substantiates the influence of three factors-namely, family living arrangements, market economic development (GDP per capita), and governmental education expenditure - on school-age children's weight. Regarding the relationship between family living arrangements and children's weight, there have been studies on the effects of parental socioeconomic status on school-age children's weight (Tang et al., 2014), but specific discussion on the impact of family living arrangements is lacking. Family living arrangements are not specifically mentioned in the social determinants of health framework proposed by WHO CSDH (2008) and Solar and Irwin 
(2010). A more significant finding of this study is that Chinese school-age children living with neither parent are more likely to face the challenges of overweight and obesity, and children living with fathers only may experience lower weight than children living with both parents. Therefore, as one of the most important contributions, this study substantiates the impact of family living arrangements on children's health, enriching the framework of social determinants of health.

This study finds that the level of economic development reflected by GDP per capita has a significant influence on school-age children's weight such that living in areas with a higher GDP per capita is associated with increased challenges of overweight and obesity. Additional research has supported the findings of this study, indicating that there are significant geographic differences in overweight and obesity rates. Chen et al. (2017) concluded that the economically advanced regions of East and North China possess the highest overweight and obesity rates, respectively, at 27. $0 \%$ and $27.9 \%$, and that the less economically developed regions of Southwest and South China have relatively low overweight and obesity rates, respectively, at $13.4 \%$ and $12.9 \%$. Swift (2011) substantiates the long-term collinear relationship between life expectancy (the health factor) and GDP (the economic factor) for all 13 OECD countries considered. In contrast, no evidence of a collinear relationship is found in this study between children's health and regional economic development in China. Additionally, the existence of unhealthy lifestyles among children living in economically developed areas may actually contribute to the high presence of overweigh and obesity in China.

In our study, the impact of governmental education expenditure on school-age children's weight is not as strong as that of GDP per capita; however, areas with high education expenditure still suffer from high proportions of child overweight and obesity. Experimental studies have found that health education expenditures can help reduce school-aged children's overweight and obesity rates in China (Xu et al., 2016). In actuality, government education expenditure is mainly used for school buildings, teachers and teaching equipment (Peng et al., 2020). Due to data constraints, this study does not explore and include other potential impact factors, such as the lack of a health education curriculum in Chinese school education, the lack of financial investment in children's health education, and the excessive emphasis on academic performance. Due to these factors, the relationship between governmental education expenditure and childhood overweight and obesity requires further in-depth research.

All three factors that constitute the welfare mix - the state (proxied by governmental education expenditure per student), the market (proxied by GDP per capita), and the family (proxied by family living arrangements)_affect Chinese school-age children to various degrees. Welfare mix theory proposes that the more the state, market, and family serve as sources of welfare provision, the higher welfare is among individuals, and the greater is the gain in personal protection (Evers, 1990, 1995). However, this study finds the opposite to be true. Children in different family living arrangements may be variably susceptible to body weight challenges, as evidenced by the prevalence of both relatively lower weight and overweight statuses, indicating that family is not always a protective factor in terms of school-age children's weight. The governmental education 
expenditure per student and GDP per capita are better defined as risk factors than protective factors in terms of school-age children's weight. Thus, Chinese schoolage children residing in economically developed areas with high investment in education are more likely to face overweight and obesity issues. Our study shows that welfare mix theory and its assumptions encounter challenges when applied to predict school-age children's weight. Researchers need to consider whether welfare investment has dual functions and in which contexts such issues arise.

One of the most important contributions of quality of life (QOL) studies is the integration of theory and practice to explore the impacts of human systems on well-being with consideration of cultural variations (Leung \& Fung, 2021; Leung \& Shek, 2019; Michalos et al., 2006; Shek, 2006, 2014). To bridge research gaps in QOL studies between Western and non-Western contexts, researchers have further explored QOL among children and adolescents in Chinese societies in studies mainly conducted in Hong Kong (Leung \& Fung, 2021; Shek \& Lin, 2017), whereas empirical studies in mainland China are still inadequate. This study identifies the effects of family and societal factors on children's weight, the influences of which may directly or indirectly impact children's QOL. Future study is needed to further examine if the relationship between children's weight and QOL is moderated by various family and societal factors. Additionally, using a sample of adolescents in mainland China, this study indicates a need for culturally sensitive health-related QOL studies with an emphasis on geographical distributions of healthcare resources and family involvement within the Chinese context.

Research based on the ecological model has found various factors affecting children's well-being and complex relations among these factors (Shek \& Siu, 2019). Research has shown material disadvantage may impose a higher risk to children's physical well-being among the contextual risk factors, whereas family and parenting variables tended to be more reliable indicators of social and academic well-being. (Ayala-Nunes et al., 2018). There are other factors affecting children's weight in addition to the three types of welfare. Therefore, future research study may turn to the ecological model to reveal the complex interplay among individual, relationship, community, and societal factors. At the same time, more family welfare variables, such as specific areas of care by family members, can be topics of future research.

This study finds statistically significant associations between Chinese schoolage children's weight (BMI-for-age percentile) and the macro factor of regional economic development (GDP per capita), between Chinese school-age children's weight and the macro factor of regional education welfare level (average government educational expenditure per student), and between Chinese school-age children's weight and the micro factor of family living arrangements. However, the effect size is relatively small due to CHNS 2011 sample limitations, and thus, the practical significance may be lower. In-depth research and comparative studies are needed to examine how family living structures impact Chinese school-age children's weight and health. Leung and Shek (2011) found problems with using a single-informant perspective to study dynamic family processes among adolescents living in poverty. Leung and Shek $(2019,2020)$ found bilateral effects of parental behavioral and psychological control on youth well-being. Therefore, for 
the influence of family on children's weight, in addition to family living arrangements, the relationship between child weight and parenting processes is worthy of future research.

\section{Conclusion and Implications}

GDP per capita has grown rapidly during the past 40 years of reform in China (Xiong \& Yin, 2016). China is advancing from a low-income country to a middle-income country. However, Chinese school-age children's physical health with regard to weight has not been in parallel with its rapid economic development. Instead, the higher GDP per capita has climbed, the more prominent the problem of school-age children's weight has become. The Chinese government has recognized the problem of childhood overweight but has not realized that schoolage children's weight is negatively linked to rapid economic development. Therefore, we recommend initiating specific health policies to allocate more resources toward resolving school-age children's weight issues-particularly overweight and obesity issues-in areas with relatively high levels of economic development.

Similarly, during China's reform and opening, governmental education expenditure has also grown rapidly (Ministry of Education of the People's Republic of China, 2012). However, Chinese school-age children's physical health with regard to weight has not been in parallel with the level of governmental education expenditure. Instead, the higher governmental education expenditure is, the more prominent the issue of school-age children's weight. Possible explanations for this finding are the potential absence or inadequacy of investments in protecting school-age children's weight health during economic development in the existing governmental education expenditure plan. Thus, in addition to establishing targeted economic and health policies, we suggest enacting economic development policies and educational development policies to include content promoting healthy weight among children in China while committing more resources to resolving and preventing school-age children's weight issues.

In addition, during China's reform and opening, population mobility and social mobility have accelerated (Bian, 2002; Duan et al., 2013; Liu et al., 2015), leading to changes in children's family living arrangements. Among all 1,656 schoolage children included in this study, $29.3 \%$ of the boys and $37 \%$ of the girls live with only one parent or with neither parent. This study further indicates that school-age children residing with neither parent and those residing with the father only are more vulnerable to underlying weight issues, as evidenced by their chances of either being overweight or experiencing relatively low weight. A possible reason for this finding is that children may experience a lack of attention and care in certain family living arrangements, resulting in a need for family-based supportive health policies to deliver more health services targeting weight.

In this study, welfare mix theory was used as the analysis framework to consider an array of social factors affecting children's weight (Evers, 1990, 1995; WHO CSDH, 2008). This research reveals that the state welfare factor (as reflected by governmental education expenditure), the market welfare factor (as 
represented by GDP per capita), and the family welfare factor (as indicated by family living arrangements) may contribute significantly to school-age children's weight issues and sometimes serve as risk factors rather than protective factors. Since welfare mix theory primarily emphasizes the protective effects of all three major welfare providers (state, market, and family), advanced theoretical and empirical research is needed to explore welfare delivery and its dual nature as both a protective factor and a risk factor. This study also indicates a need to further examine how the state, market, and family can collaboratively distribute welfare resources and mitigate potential risks during the welfare delivery process to increase children's overall well-being, especially in developing countries such as China.

Acknowledgements This research uses data from the China Health and Nutrition Survey (CHNS). We thank the National Institute for Nutrition and Health, the China Center for Disease Control and Prevention, the Carolina Population Center (P2C HD050924, T32 HD007168), the University of North Carolina at Chapel Hill, the NIH (R01-HD30880, DK056350, R24 HD050924, and R01-HD38700) and the NIH Fogarty International Center (D43 TW009077, D43 TW007709) for financial support for the CHNS data collection and analysis files from 1989 to 2015 and future surveys, Chinese National Human Genome Center at Shanghai since 2009, and Beijing Municipal Center for Disease Prevention and Control since 2011.

Funding Our work is supported by grants from the Ministry of Education of China (Grant number: 19JHQ011) and the National Social Science Foundation of China (Grant number:19ZDA144).

\section{Declarations}

Conflict of Interest We have no known conflict of interest to disclose.

Open Access This article is licensed under a Creative Commons Attribution 4.0 International License, which permits use, sharing, adaptation, distribution and reproduction in any medium or format, as long as you give appropriate credit to the original author(s) and the source, provide a link to the Creative Commons licence, and indicate if changes were made. The images or other third party material in this article are included in the article's Creative Commons licence, unless indicated otherwise in a credit line to the material. If material is not included in the article's Creative Commons licence and your intended use is not permitted by statutory regulation or exceeds the permitted use, you will need to obtain permission directly from the copyright holder. To view a copy of this licence, visit http://creativecommons.org/licen ses/by/4.0/.

\section{References}

An, M. Y. (2013). Childcare expansion in East Asia: Changing shape of the institutional configurations in Japan and South Korea. Asian Social Work and Policy Review, 7(1), 28-43. https://doi.org/10.1111/ aswp.12005

Ayala-Nunes, L., Jiménez, L., Jesus, S., Nunes, C., \& Hidalgo, V. (2018). A ecological model of wellbeing in child welfare referred children. Social Indicators Research, 140(2), 811-836. https://doi. org/10.1007/s11205-017-1807-X

Beresford, P., \& Croft, S. (1983). Welfare pluralism: The new face of Fabianism. Critical Social Policy, 3(9), 19-39. https://doi.org/10.1177/026101838300300903

Bian, Y. (2002). Chinese social stratification and social mobility. Annual Review of Sociology, 28(1), 91-116. https://doi.org/10.1146/annurev.soc.28.110601.140823 
Borrud, L. G., Chiappa, M., Burt, V., Gahche, J. J., Zipf, G., Dohrmann, S. M., \& Johnson, C. L. (2014). National health and nutrition examination survey: National youth fitness survey plan, operations, and analysis, 2012. Vital Health Stat, 2(163), 1-24.

The members of Center for Disease Control to Evaluate Trends in Obesity. (2010). National health and nutrition examination survey. In V. Preedy \& R. Watson (Eds.), Handbook of disease burdens and quality of life measures (pp. 4267). Springer.

Chen, Y., Zhang, Y., \& Kong, Z. (2017). Woguo Ertong Qingshaonian Chaozhong, Feipang Liuxing Xianzhuang Diaocha [A survey on the prevalence of overweight and obesity among children and adolescents in China]. Zhonghua Jibing Kongzhi Zazhi [Chinese Journal of Disease Control \& Prevention], 21(9), 866-869. https://doi.org/10.16462/j.cnki.zhjbkz.2017.09.002

Cobham, A., Molina, N., \& Garde, M. (2012). The child development index 2012: Progress, challenges, and inequality. Save the Children. https://resourcecentre.savethechildren.net/node/6547/pdf/6547. pdf

Cole, T. J., Bellizzi, M. C., Flegal, K. M., \& Dietz, W. H. (2000). Establishing a standard definition for child overweight and obesity worldwide: International survey. BMJ, 6;320(7244):1240-3. https:// doi.org/10.1136/bmj.320.7244.1240

Commonwealth Scientific Industrial Research Organization. (2008). User guide: 2007 Australian national children's nutrition and physical activity survey. http://www.health.gov.au/internet/main/ publishing.nsf/Content/phd-nutrition-childrens-survey-userguide

Doyle, E., Ward, S., \& Early, J. (2018). The process of community health education and promotion (3rd ed.). Waveland Press, Inc.

Duan, C., Lv, L., \& Zou, X. (2013). Major challenges for China's floating population and policy suggestions: An analysis of the 2010 population census data. China Population Today, 5(43), 17-24.

Edmiston, D. (2011). The shifting balance of private and public welfare activity in the United Kingdom, 1979 to 2007(CASE papers No.155). Centre for Analysis of Social Exclusion, The London School of Economics and Political Science. https://sticerd.1se.ac.uk/dps/case/cp/CASEpaper155.pdf

Evers, A. (1990). Shifts in the welfare mix: Introducing a new approach for the study of transformations in welfare and social policy. In A. Evers \& H. Wintersberger (Eds.), Shifts in the welfare mix: Their impact on work, social services and welfare policies (pp. 7-31). Westview Press.

Evers, A. (1995). Part of the welfare mix: The third sector as an intermediate area. Voluntas: International Journal of Voluntary and Nonprofit Organizations, 6(2), 159-182. https://doi.org/10.1007/ bf02353995

Evers, A., \& Laville, J. L. (2004). The third sector in Europe. Edward Elgar Publishing.

Gong, S., \& Li, B. (2013). Inequality in China: A case study. Australian National University.

Gonzalez-Casanova, I., Sarmiento, O. L., Gazmararian, J. A., Cunningham, S. A., Martorell, R., Pratt, M., \& Stein, A. D. (2013). Comparing three body mass index classification systems to assess overweight and obesity in children and adolescents. Revista Panamericana De Salud Pública, 33(5), 349-355. https://doi.org/10.1590/s1020-49892013000500006

Hendrie, G. A., Coveney, J., \& Cox, D. N. (2012). Defining the complexity of childhood obesity and related behaviours within the family environment using structural equation modelling. Public Health Nutrition, 15(1), 48-57. https://doi.org/10.1017/s1368980011001832

Heuer, J. O., Leruth, B., \& Mau, S. Z. K. (2016). Attitudes towards the welfare mix: How citizens in Germany and the United Kingdom attribute responsibilities for social welfare to state, market, and family - and why? Paper for the 2016 Annual ESPAnet Conference, 1-3 September 2016. Erasmus University Rotterdam.

Hu, X., Zeng, X., Zheng, L., \& Flatt, C. (2010). How does wives' unemployment affect marriage in reforming urban China? Journal of Comparative Family Studies, 41(5), 717-734. https://doi.org/10. 3138/jcfs.41.5.717

Huang, H., Radzi, W. M., \& C. W. J. B., \& Salarzadeh Jenatabadi, H. . (2017). Family environment and childhood obesity: A new framework with structural equation modeling. International Journal of Environmental Research and Public Health, 14(2), 181. https://doi.org/10.3390/ijerph14020181

Jiang, M. H., Yang, Y., Guo, X. F., \& Sun, Y. X. (2013). Association between child and adolescent obesity and parental weight status: A cross-sectional study from rural north China. Journal of International Medical Research, 41(4), 1326-1332. https://doi.org/10.1177/0300060513480081

Johnson, N. (1987). The Welfare state in transition: The theory and practice of welfare pluralism. Wheatsheaf.

Lee, M. H. (2011). Migration and children's welfare in China: The schooling and health of children left behind. The Journal of Developing Areas, 44(2), 165-182. https://doi.org/10.1353/jda.0.0104 
Leung, J. T. Y., \& Fung, A. L. C. (2021). Editorial: Special issue on quality of life among children and adolescents in Chinese societies. Applied Research in Quality of Life. https://doi.org/10.1007/ s11482-021-09915-9

Leung, J. T. Y., \& Shek, D. T. L. (2011). Poverty and adolescent developmental outcomes: A critical review. International Journal of Adolescent Medicine and Health, 23(2), 109-114. https://doi.org/ 10.1515/ijamh.2011.019

Leung, J. T. Y., \& Shek, D. T. L. (2019). The influence of parental expectations and parental control on adolescent well-being in poor Chinese families. Applied Research in Quality of Life, 14(4), 847865. https://doi.org/10.1007/s11482-017-9540-9

Leung, J. T. Y., \& Shek, D. T. L. (2020). Parental control and adolescent wellbeing in Chinese adolescents in Hong Kong. Child Indicators Research, 13(2), 703-727. https://doi.org/10.1007/ s12187-019-09642-6

Li, Y., Schouten, E., Hu, X., Cui, Z., Luan, D., \& Ma, G. (2008). Obesity prevalence and time trend among youngsters in China, 1982-2002. Asia Pacific Journal of Clinical Nutrition, 17(1), 131-137.

Liu, S. F., Lin, Y. Q., He, Z. H., Fu, R., Tan, W. Y., Ou, S. Y., \& Fang, J. Q. (2010). Shijie Weisheng Zuzhi Jiankang Diaocha Ziliao De Jiegou Fangcheng Moxing [A structural equation model for the WHO health survey data]. Zhonghua Yufang Yixue Zazhi [chinese Journal of Preventive Medicine], 44(7), 631-635.

Liu, T., Qi, Y. J., \& Cao, G. Z. (2015). China's floating population in the 21st century: Uneven landscape, influencing factors, and effects on urbanization. Acta Geographica Sinica, 70(4), 567-581.

Longo, F., Notarnicola, E., \& Tasselli, S. (2015). A framework to assess welfare mix and service provision models in health care and social welfare: Case studies of two prominent Italian regions. $B M C$ Health Services Research, 15(1), 152-152. https://doi.org/10.1186/s12913-015-0800-9

Maruo, N. (2006). A contribution to the theory of distribution and welfare. Bulletin of Policy and Management, Shobi-Gakuen University, 11, 3-17.

Michalos, A. C., Sirgy, M. J., \& Estes, R. J. (2006). Introducing the official journal of the international society for quality-of-life studies: Applied research in quality of life (ARQOL). Applied Research in Quality of Life, 1(1), 1-3. https://doi.org/10.1007/s11482-006-9013-Z

Ministry of Civil Affairs of the People's Republic of China. (2013). Minzhengbu Guanyu Kaizhan Shidu Puhuixing Ertong Fuli Zhidu Jianshe Shidian Gongzuo De Tongzhi [Notice of the Ministry of Civil Affairs on the pilot work on the construction of a moderate inclusive child welfare system]. http:// fgcx.bjcourt.gov.cn:4601/law?fn=chl393s652.txt

Ministry of Education of the People's Republic of China. (2012). Guanyu 2011 Nian Quanguo Jiaoyu Jingfei Zhixing Qingkuang Tongji Gonggao [Statistical announcement on the implementation of national education funding in 2011]. http://www.moe.gov.cn/srcsite/A05/s3040/201212/t20121231_ 146315.html

Mok, K. H., Kühner, S., \& Huang, G. (2017). The productivist construction of selective welfare pragmatism in China. Social Policy \& Administration, 51(6), 876-897. https://doi.org/10.1111/spol.12337

Murasko, J. E. (2009). Socioeconomic status, height, and obesity in children. Economics \& Human Biology, 7(3), 376-386. https://doi.org/10.1016/j.ehb.2009.04.004

National Bureau of Statistics of the People's Republic of China. (2012). China statistical yearbook 2012. China Statistics Publishing House.

National Health and Family Planning Commission of the People's Republic of China. (2018). Screening for overweight and obesity among school-age children and adolescents. http://www.chinanutri.cn/ fgbz/fgbzhybz/201804/P020180418380884895984.pdf

Peng, H. (2011). Zhongguo Zuheshi Puhuixing Shehui Fuli Zhidu De Goujian [Construction of mix of universal social welfare institution in China]. Xueshu Yuekan [Academic Monthly], 10. https://doi. org/10.19862/j.cnki.xsyk.2011.10.003

Peng, H., Qi, L., Wan, G., Li, B., \& Hu, B. (2020). Child population, economic development and regional inequality of education resources in China. Children and Youth Services Review, 110, 104819. https://doi.org/10.1016/j.childyouth.2020.104819

Powell, M., \& Barrientos, A. (2010). Welfare regimes and the welfare mix. European Journal of Political Research, 43(1), 83-105. https://doi.org/10.1111/j.1475-6765.2004.00146.x

Qiu, Z., Li, Q., Chen, D., Ma, Y., Liang, B., Wu, X., \& Hu, Y. (2014). ICF-CY Lilun Jiagou, Fangfa, Fenlei Tixi Ji Qi Yingyong [ICF-CY: Framework, approach, classification and implementation]. Zhongguo Kangfu Lilun yu Shijian [Chinese Journal of Rehabilitation: Theory and Practice], 20(1), 1-5. https://doi.org/10.3969/j.issn.1006-9771.2014.01.001 
Sasaki, S. (2011). The value of the national health and nutrition survey in Japan. The Lancet, 378(9798), 1205-1206. https://doi.org/10.1016/s0140-6736(11)61220-8

Shang, X. (2010). Jianli Guojia Zhudao De Xinxing Ertong Fuli Zhidu [Establish a new state-led child welfare system]. Shehui Fuli [Social Welfare], 12. https://doi: CNKI:SUN:MIZN.0.2010-12-010

Shek, D. T. L. (2006). Chinese family research: Puzzles, progress, paradigms, and policy implication. Journal of Family Issues, 27(3), 275-284. https://doi.org/10.1177/0192513x05283508

Shek, D. T. L. (2014). Applied research in quality of life (ARQOL): Where are we and issues for consideration. Applied Research in Quality of Life, 9(3), 465-468. https://doi.org/10.1007/ s11482-014-9340-4

Shek, D. T. L., \& Lin, L. (2017). Trajectories of personal well-being attributes among high school students in Hong Kong. Applied Research in Quality of Life, 12(4), 841-866. https://doi.org/10.1007/ s11482-016-9492-5

Shek, D. T. L., \& Siu, A. M. H. (2019). "UNHAPPY” environment for adolescent development in Hong Kong. Journal of Adolescent Health, 64(6), S1-S4. https://doi.org/10.1016/j.jadohealth.2019.01.007

Solar, O., \& Irwin, A. (2010). A conceptual framework for action on the social determinants of health. World Health Organization. https://www.who.int/social_determinants/corner/SDHDP2.pdf?ua=1

Song, Y., Wang, H. J., Dong, B., Ma, J., Wang, Z., \& Agardh, A. (2017). 25-year trends in gender disparity for obesity and overweight by using WHO and IOTF definitions among Chinese school-aged children: A multiple cross-sectional study. BMJ Chinese Edition, 20(1), 18-24. https://doi.org/10. 1136/bmjopen-2016-011904

Swift, R. (2011). The relationship between health and GDP in OECD countries in the very long run. Health Economics, 20(3), 306-322. https://doi.org/10.1002/hec.1590

Tang, W., Li, X., \& Pan, J. (2014). Zhongguo Ertong Chaozhong He Ditizhong Yu Jiating Shehui Jingji Tezheng Xiangguanxing Yanjiu [Study on the prevalence of childhood overweight and underweight, and the association with family socio-economic status (SES)]. Wei Sheng Yan Jiu [journal of Hygiene Research], 43(2), 219-223.

The China Health and Nutrition Survey(CHNS). (2020). Introduction of China health and nutrition survey projects. https://www.cpc.unc.edu/projects/china

The members of China Obesity Task Force. (2004). Zhongguo Xueling Ertong Qingshaonian Chaozhong, Feipang Shaicha Tizhong Zhishuzhi Fenlei Biaozhun [Body mass index reference norm for screening overweight and obesity in Chinese children and adolescents]. Zhonghua Liu Xing Bing Xue Za Zhi [Chinese Journal of Epidemiology], 25, 97-102.

Theobald, H. (2012). Home-based care provision within the German welfare mix. Health \& Social Care in the Community, 20(3), 274-282. https://doi.org/10.1111/j.1365-2524.2012.01057.x

Thornton, A., \& Fricke, T. E. (1987). Social change and the family: Comparative perspectives from the west, China, and South Asia. Sociological Forum, 2(4), 746-779. https://doi.org/10.1007/bf011 24383

United Nations. (1959). Declaration on the rights of the child. http://www.cirp.org/library/ethics/UNdeclaration/

United Nations. (1989). The convention on the rights of the child. https://www.unicef.org/child-rightsconvention/convention-text

van Montfort, C., Sun, L., \& Zhao, Y. (2018). Stability by change - the changing public-private mix in social welfare provision in China and the Netherlands. Journal of Chinese Governance, 3(4), 419-437. https://doi.org/10.1080/23812346.2018.1522733

Wang, L., Xu, P., Xu, J., \& Zhang, Q. (2019). 6-18 Sui Xueling Ertong Shengzhang Fayu Pingjia Zhibiao Zongshu [A review of evaluation indexes of growth and development of school age 6-18 children]. Zhongguo Xuexiao Weisheng [Chinese Journal of School Health], 40(4). https://doi.org/10.16835/j. cnki.1000-9817.2019.04.043

WHO. (2001). International classification of functioning, disability and health. World Health Organization.

WHO. (2007). 2007 WHO growth reference. World Health Organization.

WHO. (2011). The report on the World Conference on Social Determinants of Health (Rio de Janeiro, Brazil). World Health Organization.

WHO Commission on Social Determinants of Health (WHO CSDH). (2008). Closing the gap in a generation - health equity through action on the social determinants of health. Final Report of the Commission on Social Determinants of Health. World Health Organization

Whyte, M. K. (1992). Introduction: Rural economic reforms and chinese family patterns. The China Quarterly, 130, 317-322. https://doi.org/10.1017/s0305741000040741 
Xiong, J., \& Yin, S. (2016). The times series model of China's GDP per capita based on Bayesian estimation. Journal of Applied Statistics and Management, 4(8). https://doi.org/10.13860/j.cnki.sltj.20160 529-001

Xu, F., Wang, Z., Ye, Q., Tse, L. A., Xue, H., Tan, Z., \& Wang, Y. (2016). Policy-oriented, school-based physical activity intervention to prevent childhood obesity in China (the health legacy project of the second Summer Youth Olympic Games): A cluster randomised trial. The Lancet Diabetes \& Endocrinology, 4, S9. https://doi.org/10.1016/s2213-8587(16)30364-3

Yoshiike, N., Matsumura, Y., Iwaya, M., Sugiyama, M., \& Yamaguchi, M. (1996). National nutrition survey in Japan. Journal of Epidemiology, 6(3sup), 189-200. https://doi.org/10.2188/jea.6.3sup_189

Zhang, J., Ma, J., Li, B., Wu, S., Zhang, S., \& Wang, Y. (2009). Jiyu BMI Panding Chaozhong Feipang 4 Ge Biaozhun De Bijiao [Comparison of four BMI criteria for overweight and obesity]. Zhongguo Xuexiao Weisheng [chinese Journal of School Health], 30(3), 207-210.

Zhang, J., Wang, H., Wang, Z., Du, W., Su, C., Zhang, J., Jiang, H., Jia, X., Huang, F., Ouyang, Y., Wang, Y., \& Zhang, B. (2018). Prevalence and stabilizing trends in overweight and obesity among children and adolescents in China, 2011-2015. BMC Public Health, 18(1), 571. https://doi.org/10.1186/ s12889-018-5483-9

Zhang, L. (2012). A multilevel study of effects of socioeconomic status, income inequality, and the built environment on adult obesity in China [Doctoral dissertation, University of Illinois at UrbanaChampaign].Illinois Digital Environment for Access to Learning and Scholarship. https://www.ideals.illinois.edu/bitstream/handle/2142/31023/Zhang_Libin.pdf?sequence=1

Zhou, X., Moen, P., \& Tuma, N. B. (1998). Educational stratification in urban China: 1949-94. Sociology of Education, 71(3), 199-222. https://doi.org/10.2307/2673202

Publisher's Note Springer Nature remains neutral with regard to jurisdictional claims in published maps and institutional affiliations. 